\title{
IMPACT OF THE DIGITAL DIVIDE ON DIGITAL LEARNING IN ASSAM: ECONOMIC CAUSES BEHIND IT.
}

\author{
Salman Hussain, \\ M.A. in Economics, \\ Dibrugarh University,Assam \\ mail: salmanhussain3006@gmail.com \\ Navajyoti Gogoi \\ Ph.D. Rsearch Scholar, Department of Economics \\ Gauhati University, Assam \\ Email: navajyotigogoi25@gmail.com
}

\begin{abstract}
Digital learning is one of the most influential alternatives for mitigating the effects of a pandemic on the teaching-learning process. Especially in the present COVID-19 crisis, digital learning has emerged as a great alternative for continuing academic activities where the physical gathering is completely prohibited. Academic institutions and other online learning platforms take initiatives to promote digital learning process during these days, but the digital divide has stood as the main barrier in the front of it. In this paper, we have found that the digital divide is the main factor responsible for the failure of digital learning in Assam. Though there are different causes of the digital divide existed, we have limited our discussion by focusing explicitly on economic causes of the digital divide in Assam. Illiteracy, lack of skills, inadequate investment in ICT, infrastructural gap, low PCI are the major factors responsible for the digital divide in Assam.
\end{abstract}

Keywords: Digital divide, digital learning, Assam, Economic causes

\section{Introduction:}

The ongoing COVID-19 pandemic has resulted in schools shut all across the world, where globally over 1.2 billion students have been depriving of physical access to education. As a consequence of

Copyright $(\subset)$ Authors it, the popularity of e-learning process has increased very rapidly to teach remotely and on digital platforms. With this view, the educational institutions of Assam including Universities, colleges, schools have taken part to promote digital learning ${ }^{1}$ process for maintaining their academic activities. Not only educational institutions take part to promote digital learning, but many online learning platforms have come forward to provide their services freely to mitigate the effects of the Covid-19 on the teachinglearning process. But to make successful implementation of the digital learning process in Assam, digital divide ${ }^{2}$ stands as the main barrier. Digital infrastructure of Assam is not as a sound that it could make the digital learning process as a successful one. According to data published in Sandhya Keelery in July 2020, the internet penetration rate in Assam only 38\%, and more than 2500 villages in Assam yet to be covered by mobile connectivity. Besides, a large number of remote villages of the state have been depriving of getting electric facility decades after decade, where digital infrastructure is quite poor. Though the

time, place, path and/or pace.

${ }^{2}$ Digital divide implies any uneven distribution in the access to, use of, or impact of information and communication technology between any number of distinct groups, which can be defined based on social, geographical, or geopolitical criteria, or otherwise.

ISSN (Print): 2204-0595

ISSN(Online):22031731 
majority of the private schools, and colleges of the state enhanced e-learning process during these pandemic days, but most of the government educational institutions are lagging in terms of facilitating e-learning process. Sometimes, the infrastructural gap stands as a major excuse, but lack of goodwill among the teachers and administrators of the government running schools is served as another excuse. Digital divide not only bring disparity among the students to access digital learning, but it also brings disparity in terms of rich and poor, rural and urban, between educated and uneducated in the state. Some factors like poverty, infrastructural gap, illiteracy, and centralisation of the ICT sector are responsible for the digital divide within the state. Though factors from different dimensions contribute to the existing digital divide in the state, we keep our discussion limited with economic factors behind it. The present paper is an attempt to analyse the economic causes of the digital divide in Assam and its impact on ongoing digital learning in the state.

2.Objectives: The present study aims to study the following two objectives:

1. To analyse the impact of the digital divide on digital learning in Assam.

2. To discuss the economic causes of the digital divide in Assam.

3.Data sources and methodology: The present paper is quite descriptive and a comprehensive study is done about the digital divide in Assam and its impact on digital learning. All the secondary data analysed in this paper are taken from different government and non-government organisations. To make the paper comprehensive, we used different e-newspapers, research articles that are previously published in different journals.

\section{The impact of the digital divide on digital learning in Assam:}

As an instant measure of reducing the spread of Covid-19, all the educational institutions of Assam like other parts of the country have been shut since

Copyright $($ ) Authors the end of March of this year. There is the only option left to shift to digital platforms from the traditional face-to-face mode of classroom learning. Teachers and school administrators have been advised to continue communication with students through virtual lectures or portal like Massive Open Online Courses. But the major challenge stands in the front of digital learning in Assam is in the form of the digital divide. The digital divide in terms of disparity in access all the digital facilities- from electricity and internet connections to devices like computer or smart phones. Access to electricity is crucial for digital education, both for powering devices and for connecting to the internet. But frequent power cut is a common problem that has been experiencing by major parts of the state. Even about 2000 remote villages of the state did not get electrified till 2013, (Chattopadhyay, 2013), even though state government took initiatives to electrify all the remote villages of the state, but still, several remote villages have been depriving from getting electricity decades after decade, where students have to do their study with traditional lamps and solar light. Not only electricity facilitates digital learning, but electronic devices like computer, mobiles also essential for digital learning. A computer would be preferable for online classes, whereas a smart phone could also serve the purpose. If we look at the all India context, then we could find that only $24 \%$ Indians possess a smart phone, and only $11 \%$ of households possess any type of computer, which include desktops, laptops, notebooks, net books, palmtops or tablets. According to a sample survey conducted by Syed Mohsin Raja in 2014 to see the pattern of using digital media by the students of Assam, and found that $29.8 \%$ of H.S. students and $54 \%$ of the Bachelor students possessed laptop, while 93.5\% of H.S. students and $95 \%$ of bachelor students used mobile phones. But, using of mobile phones merely represents using of smart phones. Again, it could not generalise the overall using pattern of digital media by the students of Assam, since a mere use of samples, don't reflect the whole population. If we considered the latest data, we can find that internet penetration rate in Assam only ISSN (Print): 2204-0595 ISSN(Online):22031731 
$38 \%$, which is far behind from internet penetration rate in the advanced states of the country like Delhi, Kerala, and Punjab etc. Though educational institutions of Assam take initiatives to promote digital learning during this pandemic, it cannot touch all sections of the students of the state. Online classes have exposed the divide between the privileged and those who don't have access to broadband, smart phones or laptops. In some instances, parents are shelling out their savings to either buy or rent laptops or tablets for their children. But many students are missing out on lectures due to their inability to connecting with the digital world. Though some private schools, colleges and universities have successfully implemented digital learning process through conference calls, video lectures and by the other means of e-learning, students in government institutions are being left behind. It is not wondering that the backward regions of the state have more government schools than private ones, and digital learning process is more fruitfully launched in the private schools than the government schools, because of the existing gap between government and private schools in terms of their information and communication technology (ICT). Majority of the government schools, colleges in the state are seemed too

\section{Economic causes behind the digital divide in Assam:}

The causes of the digital divide in Assam are not only structural. But various political, as well as socio-economic factors are responsible for digital divide across the state. The previous researches showed that, economic factors are more influential over others on digital divide across the globe.

I. Poverty: One of the main constraints for accessing digital services by all segments of the people of Assam is the inability of the people affording electronic devices like computer, mobiles etc. According to the planning Commission's Poverty Estimates data published in 2011-12, more than $31 \%$ of the total state population had been living below the poverty line

Copyright $($ ) Authors flexible to demand regular assignments, home works from the students. Even they are not capable of adopting any initiatives for doing online classes. The problem of digital divide not only excludes many educational institutes for initiating digital learning process, but it also deprives a number of the students for accessing online classes within the same institutions that initiated the e-learning process. The dimensions of the digital divide in Assam not only found in between poor and rich, but it can also find between male and female, between age groups, between rural and urban students etc. Digital divide hampers a major no. of students of Assam to access information which is crucial for advancing their education and for coming up with innovative ideas. Presently educational institutions are embracing technology and most activities including assignments and presentation of learning material are made available online, and digital divide makes students remain void of crucial information presented online concerning academia, and thus they have always lagged. Digital divide not only stands as the main hurdle in the context of promoting digital learning during this pandemic, but it also makes obstacles for promoting distance learning program in the state.

(BPL). Besides, according to the latest data, the annual per capita income (PCI) of Assam is only Rs. 82,078 at the current price which is below than the national average. Since a significant number of state population have been living BPL and their PCI is significantly low, therefore the majority of the population of the state have to live at the subsistence level and can't afford to purchase electronic devices. Though a little number of the state population can avail all the digital facilities, the disparity in terms of rich and poor, and the rural-urban divide exist at a large scale in the state. The state government has been awarding laptops to the bright students who secured $75 \%$ marks in their HSLC exam, but the relative number of students receiving this award is limited, that it could not benefit all the students pursuing their

ISSN (Print): 2204-0595

ISSN(Online):22031731 
further study. The state government should take initiatives so that, this award could benefit more and more students.

II. Infrastructure gap: The digital infrastructure of the state is not sound enough, that it creates the problem of the digital divide within the state. Till date, a large number of remote villages of the state remain unelectrified. Moreover, due to the higher economic cost, the private telecom companies don't run their businesses in the rural areas at the extent that they run at the trade cities or centres. For most of the people who are living at the remote villages of Assam, the $4 \mathrm{G}$ network is still a dream. The digital infrastructure gap in the state creates a rural-urban divide within the state. Lack of transportation and communication facilities, coupled with the problem of electricity make some regions of the state remained digitally underdeveloped.

III. Centralisation of ICT sector: Development of the information and communication technology is the key to the development of the digital world. Though Assam has witnessed with significant growth in the ICT sector in the past decade due to the proactive initiatives taken by the state government, but the growth of the ICT sector of the state centred around the big towns, and business areas. The poor people and the people from remote villages could not be benefitted from the fruit of growing ICT sector in the state. State government need to take policy measures for universal access to ICT so that it can reduce the intra-state gap of accessing the digital services.

IV. Illiteracy: Though illiteracy is not a direct economic cause of the digital divide, it might be a significant determinant of economic soundness of a person. More a person is educated, more he has a chance to get employment. Besides the education level of a person determines his skill of communication. The lack of skill and poor communication efficiency contribute to the divide within the people. The person who has efficient communication skill is more likely to access digital services than an uneducated one. If we considered the literacy rate of Assam, then we can find that the total literacy rate of Assam is just $72 \%$ according to 2011 census data which is well below than national level. Again, the gross enrolment ratio of the state is only $17.2 \%$ according to the data published by The All India Survey on Higher Education 2016-17. Since a large number of the people of the state being illiterate, therefore it makes divide within the people whether it is on digital context or other socio-economic contexts.

Besides these some structural constraints like geographical existence and natural calamities also responsible for the digital divide in some parts of the state.

6. Conclusion and policy suggestions: To conclude, though the pace of digital learning is accelerated during these days to mitigate the effects of the present pandemic on teachinglearning process in Assam like other parts of the country, but it may not be a successful alternative due to the existing gap in the access of digital services by all segments of the students of Assam. The only way left is that the Governments need to explore new ways to expand information, infrastructure, increase access by improving markets, and reduce the cost of service, especially for internet access. To bridge the existing gap of the digital divide in the state, the Government should take necessary steps for providing alternative solutions that are cost-effective and affordable for all the people. It will be beneficial for all sections of the students if they are assigning laptop, tablet, or similar devices, and by promoting digital literacy through campaigns. Otherwise, the process of digital learning will be a complete failure in Assam, and it will make a detrimental effect upon the students belong to the weaker sections of the state during this pandemic. 


\section{References:}

1. Chattopadhyay, D. (2013). Electrification of remote villages in Assam (India): Issues and case studies. https://www.researchgate.net/publication/2 61483141】

2. Kaur, K. \& Neena (2014). Pattern of InterState Digital Divide in India. Economic Affairs, 59(3), 379-388.

3. Lee, T. (2018). The Digital Divide in Education.

4. Lokeswari, K. 7 Aiswariya, S. S. (2017). ICT Diffusion and Digital Divide: Implications for Rural Development.Journal of Content, Community and Communication, 6(3).

5. Raja, S. M. (2014). Espousal of Digital Media among the students of Assam; The state of Plateau. https://www.researchgate.net/publication/3 $\underline{09589245}$

6. Saikia, R. \& Barooah, P. K. (2019). Impact of ICT in College Libraries of Assam for Promoting Higher Education with Special Reference to Lakhimpur District. Library Philosophy and Practice. https://digitalcommons.unl.edu/libphilprac

7. Singh, S. (2010). Digital Divide in India: Measurement, Determinants and Policy for
Addressing the Challenges in Bridging the Digital Divide.

8. https://www.researchgate.net/publication/2 20136939

9. Sinha, M. K. (2012). Internet literacy skills and internet usage patterns to access e-resources by Assam university library users: an evaluative study. International Research Journal of Library, Information and Archival Studies, 1(1), 010-026.

10. https://www.researchgate.net/publication/2 64423472

11. Sinha, M. K. Studies on the Scenario of Internet Use Pattern of Assam University Community and Local Population of Barak Valley: A Survey.

12. Sipre, S. Y. \& Malik, M. (2017). Bridging Digital Divide in India: Some Factors and Initiatives. International Journal of Digital Library Services, 7(2). 